\title{
Article
}

\section{Big Data Supply Chain Analytics (BDSCA): Ethical, Privacy and Security challenges posed to business, industries and society}

Ogbuke, Nnamdi Johnson, Yusuf, Yahaya, Kovvuri, Dharma and Mercangoz, Burcu A.

Available at http://clok.uclan.ac.uk/34756/

Ogbuke, Nnamdi Johnson, Yusuf, Yahaya ORCID: 0000-0001-6045-3245, Kovvuri, Dharma ORCID: 0000-0001-9235-7194 and Mercangoz, Burcu A. (2022) Big Data Supply Chain Analytics (BDSCA): Ethical, Privacy and Security challenges posed to business, industries and society. Production Planning \& Control, 33 (2-3). pp. 123-137. ISSN 0953-7287

It is advisable to refer to the publisher's version if you intend to cite from the work. http://dx.doi.org/10.1080/09537287.2020.1810764

For more information about UCLan's research in this area go to http://www.uclan.ac.uk/researchgroups/ and search for <name of research Group>.

For information about Research generally at UCLan please go to http://www.uclan.ac.uk/research/

All outputs in CLoK are protected by Intellectual Property Rights law, including Copyright law. Copyright, IPR and Moral Rights for the works on this site are retained by the individual authors and/or other copyright owners. Terms and conditions for use of this material are defined in the policies page. 


\title{
Big Data Supply Chain Analytics (BDSCA): Ethical, Privacy and Security challenges posed to business, industries and society
}

\author{
Nnamdi Johnson Ogbuke, Yahaya Y. Yusuf, Dharma Kovvuri, Burcu A. Mercangoz \\ Lancashire School of Business and Enterprise, University of Central Lancashire, Preston PR1 \\ 2HE, United Kingdom \\ Faculty of Transportation and Logistics, Istanbul University, Istanbul, Turkey
}

\begin{abstract}
This study conducted a comprehensive review of big data supply chain analytics (BDSCA). The paper explored the application of big data in supply chain management and its benefits for organisations and society. The paper also examined the ethical, security, privacy and operational challenges of big data techniques, as well as the potential reputational damages to businesses. The review outlined four principal facets, namely: Big data analytics, applications, ethics and privacy issues, and how organisations employed this emerging tool to anticipate and even predict the future and direct their operations. These principle facets are built across the multiple levels and unique conceptual standpoints indicated by 7 themes and 14 sub-themes. These themes were generated based on 120 articles (2005 -2020) drawn mainly from leading academic journals. Overall, there is a considerable consensus across current literature that big data analytics extend far beyond just reinventing the supply chain. It has the potential to support more responsive next-generation of global companies who are operating in an increasingly challenging and uncertain environment.
\end{abstract}

Keyword: Big Data; Business Analytics; Industry 4.0; Ethical Issues; Supply Chain Management. 


\section{Introduction}

The term Big Data has garnered widespread attention since 2011 in academia, industrial community, businesses and society, and has continued to grow exponentially since then (Li et al., 2015). Although some scholars assume big data originated in the mid-nineties, with no reports of published literature work for over a decade (Lamba and Singh, 2017).

The impacts of this emerging innovation in providing relevant business insights to organisations such as Google, Amazon, Microsoft, EMC, Oracle, IBM and Facebook has led to its subsequent adoption in various industries, as well as society and government (Yang et al., 2017). This is further driven by the fact that e-commerce firms that use big data analytics (BDA) in their value chains experience 5-6\% higher productivity than their competitors (McAfee and Brynjolfsson, 2012; cited by Salleh and Janczewski, 2016). More importantly, the supply chain shocks and adaptations amid the covid-19 pandemic and post-pandemic recoveries provided indisputable evidence for the urgent needs of digital techniques for mapping supply chain networks and ensuring visibility (Ivanov and Dolgui, 2020).

Big data analytics is employed in manufacturing to enhance the intelligence and efficiency of design and applications permeate the entire manufacturing value chain, including supply chain, research and development, manufacturing and service processes (Li et al., 2015). Big data techniques reduce manufacturing developmental cycle, optimize assembly process, increase yields, and meet customer needs. Kshetri (2014) corroborated that big data has made organisations more efficient by improving their operations, facilitating innovation and adaptability, as well as optimising allocation of resources.

Due to widespread applications of big data, its definition has incorporated various dimensions. Chen et al. (2012; cited by Dubey et al., 2018) define big data as a complex process of storage, retrieval and processing of unstructured, semi-structured and structured data using suitable algorithms to extract useful information to improve the decision making skills. Einav and Levin (2013) describe big data as the availability of data in real-time, at larger scale, with less structure, and on different types of variables. According to Gartner and Brocca (2015), big data entails high-volume, high-velocity and high-variety of unstructured, semi-structured and structured information assets, largely emanating from social media, mobile phone use, product reviews and healthcare information that demand cost-effective, innovative information process, decision-making, and process automation. 
Mikalef et al. (2019) describe big data analytics as a generation of technologies and architectures, designed to economically extract value from a very large volume of a wide variety of data, by enabling high velocity capture and discovery analysis. Lamba and Singh (2017) also confirm that without technologies to capture, store, and retrieve large amounts of data, a company cannot realistically create value through big data, since the applicability of big data across diverse industries is mainly driven by developments in storage and processing technologies. Big data also enabled better exploitation of the growing amount of data and promotion of connectivity among organisations and supply chain network (Dubey et al., 2018). More so, the application of big data analytics has the potential to improve demand forecasting, communications and better management of supply chain resources, since SCM already has a set of processes and enabling systems that support business strategies and operations to achieve organisational competiveness (Niebel et al., 2018).

The authors also confirm that rapid growth and proliferation of information and communication technologies (ICTs) has greatly increased the opportunities for organisations to realize the task of integrating their supply chains. This will allow organisations to continuously improve their responsiveness and competitiveness, as well as adapting their operational strategies, methods, and technologies to near-real-time data. After all, organisations are considered as sociotechnical systems consisting of people, technologies and machines (Emery and Trist, 1960; cited by Kazemi, 2018). Therefore, harnessing the true power of data-driven insights is the holy grail of future businesses, just as the wealth of this data comes from supply chain (Harris et al., 2015).

In the vision of the industry 4.0, some scholars predicted that the digitisation of firm processes will facilitate the integration of firm functions and supply chain members, in a manner that 'chain' becomes a completely integrated ecosystem that is fully transparent to all the players involved, namely: from the supplier of raw materials, components, and parts, to the transporters of those supplies and finished goods, and finally to customers demanding fulfilment (Schrauf and Berttrain, 2016; cited by de Sousa Jabbour et al., 2018). In fact, the continuous increase in the volume and details of data captured by organisations, such as the rise in social media, Internet of Things (IoT), Cloud Computing, Cyber-Physical Systems, Machine-Learning, 3D printing, and Multimedia, have produced enormous flow of data in either structured or unstructured format (Musa and Dabo., 2016). 
According to the international data corporations (IDC, 2014), between now and 2022, the digital universe will grow by a factor of 10 - from 4.4 trillion gigabytes to 44 trillion. The IDC argued that IoT would transform the manufacturing industry over the next few years by enabling connectivity and integration between processes. It is also forecasted that there will be 26 billion connected devices by 2020 , generating global revenues of somewhere between $\$ 300$ billion and an astounding $\$ 8.9$ trillion (Brousell, et al., 2014; cited by Kazemi, 2018). Some of these benefits and opportunities offered to firms will include greater insights and visibility, and collaboration across the plant floor, as well as greater real-time machine-to-machine (M2M) connectivity (Kazemi, 2018). Again, it is estimated that overall economic gains from big data analytics would be $\$ 610$ billion in annual productivities and cost savings (McKinsey, 2013). According to Gartner (2015), organisations that adopted supply chain analytics in pursuit of a more predictive enterprise reported a high return on investment.

Despite these significant data-driven prospects, however little is known about the general application of big data analytics in the context of supply chain management (Moeuf et al., 2018). Also most of the supply chain data is not useful because of its raw state and the fact that it is often held captive inside organisational silos. Moreover, big data due to its complex and diverse functions in organisations and individuals' life, has the potential of introducing far greater security, ethical and privacy risks to customers (Salleh and Janczewski, 2016). There is also a growing but limited number of SCM-focused papers despite the increasing relevance of big data analytics across businesses and research community.

In the same vein, only few attempts have been made to comprehensively review the number of publications addressing the supply chain challenges including security, ethical and privacy concerns relating to the expansion of big data to society and industrial community (Mendez Mena et al., 2018).

Therefore, against this background, this paper will specifically contributes to the following research questions:

RQ1. How is Big Data Analytics being applied and in which ways it has improved supply chain?

RQ2. What are the ethical, security and privacy challenges associated with Big Data Analytics? 


\section{RQ3. What are the likely societal, business and governance roles in addressing these emerging technologies?}

The remainder of this paper is organised as follows: the next section will discuss big data supply chain applications, followed by security, privacy and ethical issues. Then the discussion of the research results and conclusion will be drawn from the entire overview.

\section{Literature Review}

2.1. Big data supply chain analytics

A systemic literature review of the term 'Big Data Analytics' from both academics and practitioners showed different perspectives on definition as well as the value that firms can derive from it towards the attainment of organisational goals (Mikalef et al., 2019). McKinsey described Big Data as those datasets whose size is beyond the ability of typical database software tools to capture, store, manage, and analyse supply chain information (Manyika et al., 2011; cited by Salleh and Janczewski et al., 2016). This approach gives a specific focus on the size of the data that makes them 'big' and which varies in different sectors, industries and technologies involved.

On the order hand, Chen and Zhang (2014) explored Big Data Analytics as the datasets and analytical application tool that are so large (from terabytes to exabytes) and complex (from sensor to social media data), which require advanced and unique data storage, management, analysis, and visualisation technologies. This described big data in terms of its implication in analytic functions. Several scholars have also attributed Big Data Analytics' success rate to its unique characteristics of wide variety of unstructured, semi-structured and structured data sources, which largely emanate from social media, mobile phone use, product reviews, and health care (Moe and Schweidel, 2017; Fong, Fang and Luo, 2015; Tirunillai and Tellis, 2014; Van Heerde, Leeflang and Wittink, 2000; cited by Yang et al., 2017).

Exploring this revolution will show the connectivity role of big data among organisations and supply chain networks (Dubey et al., 2018). Big data analytics provide further insights of how supply chains are formed, as well as how organisations can mobilise their capabilities and capacities in improving both internal and external organisational processes (Salleh and Janczewski et al., 2016). This illustrates the impacts of big data on physical supply chain, since supply chain management requires collaborative efforts in producing and delivery a final product from supplier's suppliers to the customer's customers. The above logic clearly 
indicates the goal of SCM in integrating both information and material flows seamlessly across the supply chain, as an effective competitive weapon (Li et al., 2015).

Some scholars have also noted that focusing on improving internal processes and efficiency is no longer enough to keep a competitive advantage (Ansari and Qureshi, 2015; Manyika et al., 2011; cited by Kusiak, 2018) as managing supply chain sustainably is imperative to reducing cost and increase agility, and making most out of the scarce resources available. Gunasekaran et al. (2016) acknowledged the impacts of Big data and Predictive analytics on supply chain performance, towards improving visibility, resilience and robustness, and further prospects that could be attained if there is commitment by top management in assimilating the technologies into the organisation's practices.

Harris et al. (2015) discusses the potential of using information and communication technologies, such as Big Data Analytics, for the optimisation of the freight transport supply chain and provided a vivid debate on how technological innovations may impact on supply chain integration. Chelbi-Gamoura et al. (2020) stated a number of opportunities at that emerge out of the intersect of SCM and Big Data Analytics whilst Zhang and Xiao (2020) investigated how data-rich environment provides unprecedented opportunities for product innovation, as well as relevant insights in understanding customer needs.

Additionally, others (Johnson, Friend and Lee, 2017; cited by Li et al., 2015) have explored the perspectives of customers as data providers, as well as sources of knowledge for new product development (NPD). There is are also the opportunities for a different emerging phenomenon, where customers are actively involved in acquiring, analysing, and acting upon data, thereby assuming the double roles of data generators and new product creators (Rindfleisch et al., 2017; cited by Mueller and Jensen, 2017). However, there remains the need to link these new emergent opportunities to firm performance on the basis of empirical evidence.

The work done by LaValle et al., (2011; cited by Lambert and Singh, 2017) outlines the need for companies to develop a data-driven business environment. The work provided case examples that underline the importance of data analysis for corporate and supply chain decisions making. Waller and Fawcett (2013) in their editorial focused on the general applicability of data science, predictive analytics, and big data in regards to SCM. They present a range of practical applications, and identify potential further research areas with the key message being that more research is required at the nexus of big data and SCM. 
The main difference between this paper and other survey papers is that we provided a more comprehensive and rigorous review of Big Data Analytics from 2005-2020, drawn from mainstream Journals. More so, we critically identified the main challenges of this disruptive technology in operations and supply chain management, particularly the key ethical, security and privacy issues posed to businesses, society and industrial community. Furthermore, our work acknowledge the growth of Industrial Internet of Things (IIoT) has increased the applicability and transformation of big data analytics across industries such as healthcare sector, science, engineering, finance, business, and eventually the society (Musa and Dabo, 2016). A good example is in pharmaceutical sector, where big data and mobile health are starting to transform the healthcare and diagnostics in a significant way, with new players such as Apple and Google acting as increasingly disruptive catalysts (Gautam and Pan, 2016; cited by Festa et al., 2018). Vaccine manufacturing firm, MERCK implemented Hadoop to utilise huge amount of data in producing vaccines faster and reduce the discard rates which were quite steep (Henschen, 2014; cited by Lamba and Singh, 2017).

Further example for big data application in the healthcare sector is the utilisation of enormous volume of information from patient data by Scientist to detect drug interactions and design to implement optimal drug therapies (healthworkscollective.com, 2014; cited by Festa et al., 2018). ). In fact, big data can help fight the spread of communicable diseases. For example, a retrospective analysis of the 2010 cholera outbreak in Haiti indicated that mining data from Twitter and online news reports could have given the country's health officials an accurate indication of the disease's spread with lead time of two weeks (Kshetri, 2014).

In banking sectors and retail industries, and in government, big data is applied extensively for analysing spending behaviour of customers, security and fraud detection, sentiment and social network analysis (Kshetri, 2014). In addition, big data can help law enforcement agencies to deploy resources more efficiently, respond quickly and increase presence in crime prone areas (Kang, 1998). Big data also enhances retail supply chain, which heavily depends on the availability of accurate and up-to-date information for demand forecast and other business execution (Gunasekaran et al., 2016).

According to Schoenherr and Speier-Pero (2015; cited by Bumblauskas et al., 2017), nearly 50 percent of supply chain professionals were using BDA or had plans to use BDA in the near future. These professionals saw BDA as an enabler for better decision making, as well as a predictive analytical tool to achieve performance advantages (Bumblauskas et al., 2017). 
Raman et al. (2018) have also noted that the concept of big data helps to improve visibility by providing an integrated framework for monitoring performance and customer interaction through real-time data analysis and critical decision-making scenarios. Thus militating risk and supply chain disruption and failures.

According to IBM's Big data and Analytics Hub (2014), "10 billion mobile phones will be in use by 2020, 294 billion emails are sent every day, and trillion of sensors monitor, track with each other, populating the Internet of Things with real time data". Several supply chain literature (Baihaqi and Sohal, 2013; Li et al., 2009; Prajogo and Olhager, 2012; Vickery et al., 2003; cited by Raman et al., 2018) have acknowledged that the use of various information technologies such as Enterprise Resource Planning (ERP), Global Positioning System (GPS), Radio Frequency Identification (RFID), and Electronic Data Interchange (EDI) in operations and supply chain management enabled firms to effectively maintain control over their information, material and financial flows.

Additional example of companies that adopt big data analytics and customer profiling are Amazon and Wal-Mart (Accenture, 2014). They utilise technologies to monitor, track, and secure millions of items in their inventories and rely on forecasting analytics for their 'anticipatory shipping', thereby predicting when customers will purchase a product and preship it to a depot close to the final destination (Rozados and Tjahjono, 2014; cited by Niebel et al., 2018). Similarly, Ford Motor Company, employed big data in capturing consumer data from vehicles through sensors and remote app-management software (Niebel et al., 2018). Based on the analysis of data from their cars' voice recognition systems, the company found out that the surrounding noise affected the performance of the software, which led to the improvement of the system through noise reduction technology and repositioning of microphone. These examples indicate the applicability of big data analytics, particularly in operations and supply chain, especially in its decision-making capacity, which ensure process improvement, management of logistics activities, enhancement of inventory management, and cost optimisation.

However, despite the impacts of these disruptive technologies, it required guidance and interpretation by people who knew the tools as well as the business, including the supply chain operators. According to Lamba and Singh (2017), big data provided limited real-time applications in the context of functional areas of operations and supply chain management such as procurement, production, logistics and forecasting. In addition, the author argued that there 
are certain barriers to implementing predictive analytics, such as the lack of skilled professionals, lack of awareness and dearth of tools for training the next generation of data scientists in the supply chain industry.

Alter et al. (2013; cited by Yang et al., 2017) went further to highlight three kinds of expertise needed in supply chain data science, namely: Technological knowledge about the tools and technology capability, functional knowledge about supply chain management, and mathematical knowledge of algorithms. The authors maintained that the blend of these three skillsets will enable companies combine data into new insights for the enterprise-decision making. Accordingly, these skillsets are in short supply now and for the foreseeable future, across all areas of business, including supply chain sector. Yang et al., (2017) echoed that the major difficulties lie in data capture, storage, searching, sharing, analysis, and visualisation. The authors warned that if organisations failed in surmounting these major skillsets gap, Big Data will become a gold mine that firms lacked the capabilities to explore.

Against this background therefore, this study offers useful contribution by addressing the research question:

\section{RQ1. How is Big Data Analytics being applied and in which ways it has improved supply chain?}

\section{Ethical, Privacy and Security challenges of big data business analytics}

Tremendous progress has been made in computing power, storage capacity, and software, resulting in an increased surge in big data technologies (Pauleen et al., 2017; cited by Maple, 2017). This upsurge, has brought several privacy concerns (Biajian et al., 2018). Similarly, it has also led to the growth in the number of smart devices and the speed of that growth present challenges, particularly security and privacy issues to society and individuals' freedom, as government battle to develop policies, standards and laws that shape this development (Maple, 2017).

The question is whether such laws and regulations offer adequate protections for individuals' data, especially when it relates to Internet of Things. Of course, there is no known new laws that address this emerging phenomenon. Instead, they are governed by existing legal framework. In the UK for example, personal data remains subject to the Data Protection Act of 1998. Although, there is a new proposed regulatory framework by UK government that will improve citizens' online safety (Online Hams Whitepaper, 2019). 
Moreover, the characteristics of big data are tightly linked to privacy, ethical and security effects to customer welfare and these fallouts have attracted the attention of scholars, businesses, society, industries and policy makers (Kshetri, 2014). According to ISACA 9 (2014) and Kshetri (2014) huge amount of data means that security breaches and privacy violation are likely, which can cause severe consequences and losses, leading to reputational damage, legal liability, ethical harms and other amplified technical issues. Further, Laney (2001) outlined some factors that can necessitate these challenges, namely: (1) the enormous amount of data (volume), (2) a wide variety of data coming from highly diverse sources (variety), and (3) the pace of data processing (velocity). Therefore, the greatest challenge now is to find new ways of storing and processing these different types of data, since the old databases are mainly structured for only one type of data (Chen et al., 2014 and Hofmann, 2017). The analysis of these data, extraction of insights and appropriation of its values, without any infringement to ethical, security, and personal privacy data protection, presents a key challenge to not only business but also society. Therefore, against this background, this paper will attempt to answer the following research questions:

RQ2. What are the ethical, security and privacy challenges associated with Big Data Analytics?

\section{RQ3. What are the likely societal, business and governance roles in addressing these emerging technologies?}

\subsection{Ethical issues}

The importance of ethics is very significant in big data analytics, especially when it comes to profiling of users through social media analytics. At the same time, people are increasingly becoming aware of how their personal data are being used, even as some individuals and firms are very keen to trade personal data for commercial gains. Therefore, specific laws and regulations must be established to preserve the personal and sensitive information of customers, as no specific laws address these invasive and intrusive technologies.

Some data will need more protection than others. For example, a sensor tracking pallets, being shipped overseas is unlikely to transmit such sensitive personal data by comparison with a wearable fitness device, which for instance, might be transmitting medical information. It is also clear that connected devices are often located in intimate spaces such as the home and car or the case of smart pills that are ingested into the body. Hence, this increases the sensitivity 
of personal data transmitted by such devices to companies. Sadly enough, the recent Facebook personal data 'abuse' story ignored this duty of care to its customer (Mikalef et al., 2019).

Consequently, breaching this perceived duty of care could lead to poor customer loyalty, civil litigations, and reputational damages to businesses. A case in point is business initiatives that rely on collection of large data from click-stream and GPS from mobile devices, which is used to make a short-term prediction with high level of accuracies. Such firms have also met with stiff resistance from customers (Taylor et al., 2014; cited by Kshetri, 2014). So, there are serious ethical issues in the use of private data and this exploitation of private data is likely to create barriers in future business engagements. These business practices pose threat for some organisation as well as create opportunities for others. Although the ethics of using data analytics and the inherent implications for organisations is still very limited in the existing literature (Mikalef et al., 2019). It is important that firms not only comply with legislation, but also follow ethical rules during collection, managing, and analysing the data. Therefore, there is an urgent need for firms to build an image as a trustworthy entity for their customers. As such, improving security or obtaining consent for internet-connected devices has become increasingly important.

\subsection{Privacy issues}

As technology progresses, more smart devices and appliances are given the capability of connecting to network and creating conveniences for users. Although the benefits of these devices are significant, the potential downsides can be created when improper implementation protocols are used to communicate information among networks. Therefore, it is important to measure the security of these connections. According to Buenrostro et al. (2018), transmitting data could give sensitive details about owner's health or religion, just as faulty provision of data confidentiality and integrity could also influence users' privacy as malicious parties can breach personal information without any authorisation or consent (Biajain et al., 2018; cited by Mikalef et al., 2019). There is a growing concern amongst customers over lack of privacy protection for their data by organisations' data collection methods, especially with respect to the use of tracking technologies, such as cookies and GPS trackers.

For example, a survey carried out by Pew Internet and America Life Project (2012) suggests that 30 per cent of smartphone owners agreed they would turn off their location tracking features due to concerns that others would access their information. Another good example is the Global Consumer Sentiment study conducted by BCG (2013), where privacy of personal 
data protection was a top issue for over 75 percent of participants. In facts, only 7 percent of the participants were willing to allow their information to be used for purposes other than it was originally collected for (Kshetri, 2014).

The above examples highlighted the growing security challenges of internet of things on smart appliances from hardware and software cryptology to operating systems usage across different platforms, which require new regulatory frameworks to tackle (Buenrostro et al., 2018).

\subsection{Security issues}

The security challenges posed by the surge in big data technology and internet-connectivity of smart devices seems to be unabated. It is predicted that by the end of 2020, there will be around 20 billion connected devices (Gartner, 2015). This indicates that data exchange over the network will be greater than 40 Zettabytes for the same period (Forbes, 2016; cited by Yucelen et al., 2016). In addition, most of these data comes in multiple formats such as structured and unstructured. Although the main concern is much of the unstructured data in the form of text data, e-mails, instant messages, audio and video images, road traffic information and multimedia objects, which are sensitive in nature and may contain personal identifiable information (PII) and intellectual property (IP) (Yucelen et al., 2016).

According to Elmaghraby and Losavio (2014), security includes illegal access to information and attacks causing physical disruptions in services availability, as well as placement of tracking devices without permission. More so, security threats such as privacy, confidentiality and integrity are magnified by the volume, velocity, and variety of big data, which worsen when using cloud computing platform (Musa and Dabo, 2016). Electronic surveillance may also constitute security breach when government violates a subjective expectation of privacy that society recognises as reasonable.

Meanwhile, cyber security is another threat, which is an unauthorised access to a computer, a network and related data, an authorised interception, inference or transmission of data processes and analysis of data collected. According to Yucelen et al. (2016), users are also vulnerable to these adversarial cyber-attacks with drastic society ramifications. For example, attackers can gain access to computing platforms and manipulate systems measurement data which can compromise systems performance and integrity, and hence, security and safety in cyber-physical systems. Therefore, the issues of data security also required special consideration from supply chain perspectives as companies are increasingly dependent on information, which may well originate beyond a single company. Cyber security is valued as a 
major challenge in supply chain, as this technique can compromise companies and make them inevitably lose control over customers' and products' propriety information. It is the responsibility of firms to ensure users' and products' data are not shared without owner's consent (Kache and Seuring, 2015; cited by Awwad et al., 2018)). Moreover, Awwad et al. (2018) confirm that with the advent of big data and integration with SCM, there are considerable threats to data security across the supply network. In this regards, the development of secure security architecture is required to prevent infringement of client's privacy and ensure controlled access.

However, according to Kshetri (2014), a number of companies are engaged in questionable data collection and sharing practices. An example was the 2012 case, when a security blogger revealed how Nisan, without warning the owners, reported location, speed and direction of its Leaf brand cars to website that other users could access through built-in RSS feed readers. Likewise, there are reports that iPhone and Android phones have been secretly sending information about users' location to Apple and Google. Another instance was in 2010, when an Italian court found three YouTube executives guilty of violating a child's privacy.

In general, the above literature have highlighted the broad range and scale of ethical and privacy challenges associated with big data and other internet technologies. But the societal and users' perspectives over the lack of responsibility in offering that duty of care by internet owners remained unchanged. There is also the inability of government to introduce new and effective laws that will replace the underdeveloped regulations and regulatory security infrastructure. Clearly from the above discourse, there are lack of significant efforts on side of the government, in terms of a regulatory framework and the adequate awareness on the part of society that may have given rise to customer exploitation by firms (Kshetri, 2014).

\section{Methodological Approach}

To address the research questions, the study identified the following research questions which defined 3-step approaches (Table 1). The study adopted a systematic literature review process that entails a structured and transparent assessment of the articles from mainstream academic journals. The review showed different perspectives on the definition of Big Data Analytics and Supply Chain and widespread applications of Big Data in Supply Chain Management by firms to gain competitive advantage. The research also discussed the security, privacy and ethical challenges confronting businesses, society and industry. 
It significant to broaden the research with the inclusion of relevant articles, given the nature of the research topic. The key stages of SLR comprise planning, execution and reporting.

Table 1. Research questions and step approaches

\begin{tabular}{|l|l|}
\hline Questions & Step \\
\hline $\begin{array}{l}\text { How is Big Data Analytics being applied and in } \\
\text { which ways it has improved supply chain? }\end{array}$ & $\begin{array}{l}\text { Define the concept of Big Data Supply Chain } \\
\text { Analytics and impacts in Supply Chain }\end{array}$ \\
\hline $\begin{array}{l}\text { What are the ethical, security and privacy challenges } \\
\text { associated with Big Data Analytics? }\end{array}$ & $\begin{array}{l}\text { Identify the ethical, security, and privacy challenges } \\
\text { associated with Bid Data }\end{array}$ \\
\hline $\begin{array}{l}\text { What are the likely societal, business and } \\
\text { governance roles in addressing these emerging } \\
\text { technologies? }\end{array}$ & $\begin{array}{l}\text { Outline the likely Societal, Business and } \\
\text { Governmental roles in addressing the Impacts of } \\
\text { Big Data Analytics }\end{array}$ \\
\hline
\end{tabular}

This study entails a review scope of about 14 years and once this timeframe has been established, the research team agreed a set of keywords for the literature search. The keywords provided clues and clear directions for the review protocol (Table 2). The review indicates that Big Data Analytics have become increasingly an enabling tool that provides useful insights of decision making capabilities for organisations that have adopted them.

\section{Data Analysis}

The research papers reviewed were extracted from prominent databases like Tailor and Francis, Emerald, Science Direct, Elsevier, Ebsco, and Google Scholar. The articles considered in this study were published between 2005 - 2020. The keywords used are stated in Table 2. Initially, 2,042 articles were obtained from a vast array of journals. A preliminary screening of articles was then performed by assessing titles and abstracts to filter the articles based on relevance. The articles in non-English language were discarded. The screening generated 320 articles and rigorous analysis of these articles were performed to limit the system boundary of the articles to big data supply chain analytics, industry 4.0, ethical, security, and privacy issues. Repetitive and similarity articles were removed, leading to 120 most relevant articles from 48 leading Journals as shown in Table 3. 
Table 2. Review protocol

\begin{tabular}{|l|l|}
\hline Research Variables & Descriptions \\
\hline Database & $\begin{array}{l}\text { The study selected Scopus because it offers integrated results from diverse } \\
\text { databases, including Tailor and Francis, Elsevier, Science Direct, Emerald, } \\
\text { and Ebsco. }\end{array}$ \\
\hline Article quality & $\begin{array}{l}\text { This paper addressed the issues by considering articles that originate from } \\
\text { ABS Journal ranking and SSCI index (impact factor). }\end{array}$ \\
\hline Review scope & $\begin{array}{l}\text { The year, 2005 is selected as the baseline for the literature search. This will } \\
\text { support the objective of the present research. Therefore, review considers } \\
\text { the timeline from 20005-2020. }\end{array}$ \\
\hline Keywords & $\begin{array}{l}\text { Big Data; Business Analytics; Internet of Things; Industry 4.0; Ethical } \\
\text { Issues; Supply Chain Management. }\end{array}$ \\
\hline Article selection criteria & $\begin{array}{l}\text { The principal criteria include articles with good empirical characteristics, } \\
\text { including quantitative survey, case study and conceptual model } \\
\text { development, as well as reviews that focused on Big Data Supply Chain } \\
\text { Analytics, applications, and ethical issues. }\end{array}$ \\
\hline $\begin{array}{l}\text { In line with the objectives and review scope of this research, the articles } \\
\text { were restricted and limited to a manageable number. We reviewed articles } \\
\text { with conceptual underpinnings inherent in the research questions. } \\
\text { However, papers based on stochastic mathematical models were excluded } \\
\text { from the review. The articles of interest must also have management } \\
\text { implications for supply chain and operations applications. Articles that did } \\
\text { not address the challenges of big data supply chain analytics were also } \\
\text { excluded. }\end{array}$ \\
\hline
\end{tabular}

\subsection{The thematic landscape of BDSCA}

The 120 articles were classified into thematic landscape across the 48 mainstream journals used. The thematic landscape provided useful insights into, and the journey involved in, the emergence of Big Data Supply Chain Analytics (BDSCA). Additionally, thematic landscape was designed and developed around a conceptualised framework along five-level themes, namely: 
Table 3: Classification of the Reviewed Articles

\begin{tabular}{|c|c|c|c|}
\hline Journal & $\begin{array}{l}\text { Article } \\
\text { Count }\end{array}$ & Journal & $\begin{array}{l}\text { Article } \\
\text { count }\end{array}$ \\
\hline International Journal of Production Research & 19 & Journal of Computer Engineering & 1 \\
\hline $\begin{array}{l}\text { International Journal of Operations and } \\
\text { Production Management }\end{array}$ & 4 & International Journal of Supply Chain Management & 6 \\
\hline Production Planning and Control & 10 & Cyber Physical System & 1 \\
\hline Business Process Management Journal & 3 & IEEE Internet of Things Journal & 1 \\
\hline Journal of Advanced Research & 4 & Digital Investigation & 1 \\
\hline Annals of Operations Research & 1 & & \\
\hline International Journal of Logistics Management & 1 & Economics and Finance & 1 \\
\hline Benchmarking: An International Journal & 1 & Technology in Society & 1 \\
\hline Journal of Industrial Marketing Management & 1 & Procedia Computer Science & 2 \\
\hline Cyber Physical Systems & 7 & Supply Chain Forum: An International Journal & 1 \\
\hline Computer in Human Behaviour & 1 & & \\
\hline International Journal of Production Economics & 13 & Journal of Cyber Policy & 4 \\
\hline Information Systems & 2 & Advances in Mechanical Engineering & 1 \\
\hline $\begin{array}{l}\text { International Journal of Engineering and } \\
\text { Techniques }\end{array}$ & 1 & Information, Communication and Society & 1 \\
\hline European Journal of Information Systems & 1 & International Journal of Digital Earth & 1 \\
\hline \multirow[t]{2}{*}{$\begin{array}{l}\text { Information Security Journal: A Global } \\
\text { Perspective }\end{array}$} & 1 & $\begin{array}{l}\text { System Science and Control Engineering: An open } \\
\text { Access Journal }\end{array}$ & 1 \\
\hline & & Journal of Business Research & 5 \\
\hline Journal of Cyber Security Technology & 4 & Future Generation Computer Systems & 1 \\
\hline $\begin{array}{l}\text { International Journal of Logistics Research and } \\
\text { Applications }\end{array}$ & 3 & Computers in Human Behaviour & 1 \\
\hline International Journal of Systems Science & 1 & $\begin{array}{l}\text { Journal of Economics of Innovation and New } \\
\text { Technology }\end{array}$ & 1 \\
\hline Journal of Broadcasting and Electronic Media & 1 & Journal of Network and Computer Applications & 1 \\
\hline Intelligence and National Security & 1 & Journal of Telecommunications Policy & 2 \\
\hline Information Sciences & 1 & Financial Times & 2 \\
\hline Business Systems Research & 1 & $\begin{array}{l}\text { Big Data Analytics in Operations and Supply Chain } \\
\text { Management }\end{array}$ & 1 \\
\hline
\end{tabular}


Big Data Analytics, Applications, Ethics, Privacy and Security. Each level contains article stream that characterised the group sub-themes. Following this was the selected article with the full list of the authors. This segment gives the descriptions of the authors' viewpoints around the discourse. The summary of these above points are shown in Table 4.

Moreover, the matrix level was explored based on broad theme and sub-themes. This was done in a way that shows a progressing expansion of conceptual framework, from bottom-up to topdown approach. The bottom-up approach is the beginning of the extraction of sub-themes, as individual research articles in the review were determined inductively. The coding was designed in a manner that allowed the capturing of the most dominant conceptual standpoints in the articles towards the main issues of privacy and security, as well as on how big data analytics can enhance economic efficiency, improve access to social services, as well as increase innovative platform for information and communications.

To ensure validity and reliability of the coding, the research team read the articles in chronological order starting from 2005 to 2020. Separate lists were generated and crossvalidated. There were discussions among the research team about the classification of the themes and sub-themes and consensus were reached. In general, the reconciliation of the useful insights arising from the top-bottom and bottom-up approaches were achieved within the research team and the team adopted the four principal facets of BDSCA development, namely: big data analytics, applications, ethics and privacy - for representing the conceptual matrix at the top-most level. The next section explained the results in details. 
Table 4: Thematic landscape in terms of broad themes and sub -themes (article streams)

\begin{tabular}{|c|c|c|}
\hline $\begin{array}{l}\text { BDSCA(the number):broad theme reflecting } \\
\text { the main focus }\end{array}$ & $\begin{array}{l}\text { Article stream (Number): showing the } \\
\text { conceptual underpinning of the sub-them } \\
\text { focus }\end{array}$ & $\begin{array}{l}\text { Conceptual standpoints of selective articles } \\
\text { (full list of the authors) }\end{array}$ \\
\hline
\end{tabular}


Table 4: Thematic landscape in terms of broad themes and sub -theme (article streams)

\begin{tabular}{|c|c|c|}
\hline $\begin{array}{l}\text { BDSCA(the number): broad theme reflecting } \\
\text { the main focus }\end{array}$ & $\begin{array}{l}\text { Article stream (number): showing the } \\
\text { conceptual underpinning of the sub-theme } \\
\text { focus }\end{array}$ & $\begin{array}{l}\text { Conceptual standpoints of selective articles } \\
\text { (full list of the authors) }\end{array}$ \\
\hline & $\begin{array}{l}\text { Article (stream 5): there are more focus in } \\
\text { employing machine learning through } \\
\text { uploading of information and making } \\
\text { predictions about the future behaviour based } \\
\text { on behavioural residues and interpretation of } \\
\text { individuals' footprints. } \\
\text { Article (stream 6): Similar focus on other } \\
\text { related advanced technology such as cloud } \\
\text { computing to mitigate the time-demanding } \\
\text { and challenging task, which required } \\
\text { computational infrastructure to ensure } \\
\text { successful data processing and analysis. }\end{array}$ & $\begin{array}{l}\text { Din et al. (2019) investigates how Machine- } \\
\text { learning used behavioural residue in digital } \\
\text { footprints to assess and drive personality } \\
\text { predictions, particularly in examining Anxiety in } \\
\text { micro-blogs from social media tweets. This } \\
\text { particular technique is new, and it is limited to } \\
\text { healthcare sector. In addition, the research by } \\
\text { Zhaodan et al. (2016; cited by Gruda and } \\
\text { Souleiman. 2018) provided a link between } \\
\text { machine-learning and cyber-physical systems } \\
\text { performance. However, the article showed } \\
\text { limited managerial inputs in SCM in terms of the } \\
\text { applicability of this technology. } \\
\text { Presenting findings on how Supply Chain (SC) } \\
4.0 \text { can gain competitive advantage, the research } \\
\text { by Makris et al. (2019) focus on three key } \\
\text { emerging developmental trends: Big data, Cloud } \\
\text { Computing and } 3 \text { D printing. Although the article } \\
\text { presents graphical framework but show } \\
\text { limitations in understanding the issues around } \\
\text { adaptability, strength and challenges. }\end{array}$ \\
\hline
\end{tabular}


Table 4: Thematic landscape in terms of broad themes and sub -theme (article streams)

\begin{tabular}{|c|c|c|}
\hline $\begin{array}{l}\text { BDSCA(the number):broad theme } \\
\text { reflecting the main focus }\end{array}$ & $\begin{array}{l}\text { Article stream (number): showing the } \\
\text { conceptual underpinning of the sub-theme } \\
\text { focus }\end{array}$ & $\begin{array}{l}\text { Conceptual standpoints of selective articles } \\
\text { (full list of the authors) }\end{array}$ \\
\hline $\begin{array}{l}\text { Applications (1): Big data application } \\
\text { complements decision support systems } \\
\text { (DSS), foster complex decision-making and } \\
\text { help problem solving in supply chain } \\
\text { management. }\end{array}$ & $\begin{array}{l}\text { Article stream (8): Big data is also used for } \\
\text { positioning of goods on the shop shelves as } \\
\text { well as employed to get a better handle on } \\
\text { company account, manage regulatory } \\
\text { requirements and cost savings. }\end{array}$ & $\begin{array}{l}\text { Tan et al. (2015), for example, highlighted the } \\
\text { potential of Big data as a source for supply chain } \\
\text { innovation. Being an interesting contribution to } \\
\text { research at the nexus of Big data Analytics and } \\
\text { SCM, the proposed analytical structured } \\
\text { approach enables companies to integrate their } \\
\text { supply chain innovation competencies with } \\
\text { supply chain partners systematically, leveraging } \\
\text { Big data Analytics insights. In an increasingly } \\
\text { competitive and fast-paced business } \\
\text { environment, the article's promoted extension } \\
\text { of the innovation capability into the supply } \\
\text { chain seems a promising strategy, considering } \\
\text { that crucial knowledge may reside outside a } \\
\text { single company. The article presented by } \\
\text { Sabashini and Kavitha (2011) contributes to the } \\
\text { theory development in SCM through } \\
\text { investigation of the potential impact of Big Data } \\
\text { Analytics on information usage in a corporate } \\
\text { and supply chain context. The paper provided } \\
\text { insights into the opportunities and challenges } \\
\text { emerging form the adoption of Big Data } \\
\text { Analytics in SCM. } \\
\text { Drawing from resource-based view, Chavez et } \\
\text { al. (2017) investigated the linkage between } \\
\text { data-driven supply chains, manufacturing } \\
\text { capability and customer satisfaction. The } \\
\text { research outcomes suggest that data-driven } \\
\text { supply chain are positively associated with } \\
\text { manufacturing competitiveness dimensions } \\
\text { such as quality, delivery, flexibility, and cost, } \\
\text { which in turn leads to customer satisfaction. } \\
\text { Addressing the challenges linked to the growing } \\
\text { amount of data, a major problem in modern } \\
\text { manufacturing, Zhang et al. (2015) present an } \\
\text { integrated approach for optimised logistics } \\
\text { management on the shop floor, based on the } \\
\text { smart manufacturing concept, using production } \\
\text { resources equipped with RFID facilities. }\end{array}$ \\
\hline
\end{tabular}


Table 4: Thematic landscape in terms of broad themes and sub -theme (article streams)

\begin{tabular}{|c|c|c|}
\hline $\begin{array}{l}\text { BDSCA(the number):broad theme } \\
\text { reflecting the main focus }\end{array}$ & $\begin{array}{l}\text { Article stream (number): showing the } \\
\text { conceptual underpinning of the sub-theme } \\
\text { focus }\end{array}$ & $\begin{array}{l}\text { Conceptual standpoints of selective articles } \\
\text { (full list of the authors) }\end{array}$ \\
\hline $\begin{array}{l}\text { Applications (2): Business intelligence and } \\
\text { analytics are enhanced with Big data for } \\
\text { decision on strategy, managing optimisation } \\
\text { and competition. }\end{array}$ & $\begin{array}{l}\text { Article stream (9): the focus is centred on the } \\
\text { prediction that Big data would improve } 60 \\
\text { per cent of existing business and will foster } \\
\text { new businesses in the next decade. } \\
\text { Article stream (10): the focus in real-time } \\
\text { information processing technology based on } \\
\text { RFID and NFC in IoT will be widely used in } \\
\text { supply chain. As result, the demand forecast } \\
\text { would be more accurate and extra buffers } \\
\text { would be unnecessary. }\end{array}$ & $\begin{array}{l}\text { Opresnik and Taisha (2015; cited by Wemba et } \\
\text { al., 2015) linked the advantages of Big Data to the } \\
\text { business strategy of servitisation. Their proposed } \\
\text { strategic framework outlines how companies can } \\
\text { extend their value portfolio by adding information } \\
\text { as the pillar alongside the traditional aspects of } \\
\text { product and service. Barbaray et. (2018; cited by } \\
\text { Fatorachian and Kazemi, 2018) reviewed research } \\
\text { on Industry } 4.0 \text { concerning issues of SMEs and } \\
\text { suggested that SMEs adopt Industry } 4.0 \text { concepts } \\
\text { only for monitoring industrial processes. } \\
\text { Presenting findings from a systematic review and } \\
\text { longitudinal case study, the research by Wemba et } \\
\text { al. (2015) provides a comprehensive overview of } \\
\text { a range of Big Data concepts. On a more granular } \\
\text { level, the authors assessed how the generation of } \\
\text { business value is supported by application of Big } \\
\text { Data concepts where a key focus was on Big Data } \\
\text { strategy as well as Big Data implementation. In } \\
\text { this way, the paper prepares the ground for future } \\
\text { research at the intersection of Big Data Analytics } \\
\text { and SCM. However, some crucial aspects such as } \\
\text { the financial implications of Big Data Analytics } \\
\text { adoption in SCM or the potential of Big Data } \\
\text { Analytics with regards to enhancing the } \\
\text { innovation and product design capabilities across } \\
\text { the supply chain were not touched upon. Chelbi } \\
\text { et al. (2020) stated several opportunities that will } \\
\text { emerge when SCM intersects with Big Data } \\
\text { Analytics. Unfortunately, how analytics can be } \\
\text { applied to supply chain processes is remain } \\
\text { unclear in their work. }\end{array}$ \\
\hline
\end{tabular}


Table 4: Thematic landscape in terms of broad themes and sub -theme (article streams)

\begin{tabular}{|c|c|c|}
\hline $\begin{array}{l}\text { BDSCA(the number):broad theme } \\
\text { reflecting the main focus }\end{array}$ & $\begin{array}{l}\text { Article stream (number): showing the conceptual } \\
\text { underpinning of the sub-theme focus }\end{array}$ & $\begin{array}{l}\text { Conceptual standpoints of selective articles } \\
\text { (full list of the authors) }\end{array}$ \\
\hline $\begin{array}{l}\text { Applications (3): smart manufacturing } \\
\text { utilises the concept of cyber-physical } \\
\text { systems spearheaded by internet of } \\
\text { things }\end{array}$ & $\begin{array}{l}\text { Article stream (11): the focus is on manufacturing } \\
\text { floor, where physical internet system is employed to } \\
\text { convert typical logistics resources into smart } \\
\text { manufacturing objects (SMOs) by using Internet of } \\
\text { Things (IoT) and wireless technology to create a } \\
\text { RFID-enabled shop floor environment. Big data } \\
\text { convert typical production resources such as workers, } \\
\text { machines, materials into smart manufacturing objects } \\
\text { (SMO). } \\
\text { Article stream (12): more so through Wi-Fi or } \\
\text { Bluetooth, SMOs create an intelligent manufacturing } \\
\text { shop floor where interconnection, interoperation, and } \\
\text { interaction fashion is achieved. }\end{array}$ & $\begin{array}{l}\text { The research conducted by Chang et al. (2017) } \\
\text { advanced the concept of physical internet and } \\
\text { big data analytics for RFID logistics data by } \\
\text { defining different behaviours of smart } \\
\text { manufacturing objects (SMOs). The concept } \\
\text { promotes the intelligent packaging for } \\
\text { manufacturing resources, as well as configuring } \\
\text { an adaptive workflow for manufacturing } \\
\text { process. Bahroun et al. (2018; cited by } \\
\text { Oberlander et al., 2018) explored the role of } \\
\text { Internet of Things (IoT) and its impact on supply } \\
\text { chain management. The study categorises } \\
\text { existing literature based on the methodology, } \\
\text { industry sector, and supply chain processes. } \\
\text { Maple (2017) discussed the evolution of IoT, its } \\
\text { various definitions, and some of its key } \\
\text { application areas. The author pointed to the } \\
\text { growth in the number of devices and how the } \\
\text { speed of that growth presents challenges to our } \\
\text { society and freedom as we battle to develop } \\
\text { policies, standards, and governance that shape } \\
\text { this development. }\end{array}$ \\
\hline
\end{tabular}


Table 4: Thematic landscape in terms of broad themes and sub -theme (article streams)

\begin{tabular}{|c|c|c|}
\hline $\begin{array}{l}\text { BDSCA(them number):broad theme } \\
\text { reflecting the main focus }\end{array}$ & $\begin{array}{l}\text { Article stream (number): showing the } \\
\text { conceptual underpinning of the sub- } \\
\text { theme }\end{array}$ & $\begin{array}{l}\text { Conceptual standpoints of selective articles (full } \\
\text { list of the authors) }\end{array}$ \\
\hline $\begin{array}{l}\text { Ethics (1): there should be an increase } \\
\text { sensitivity of any personal data transmitted } \\
\text { by connected devices and companies should } \\
\text { be keen to monitor all private activities. }\end{array}$ & $\begin{array}{l}\text { Article stream (13): the focus is on the } \\
\text { connected devices located in the intimate } \\
\text { spaces such as the home and car or the case } \\
\text { of smart pills that ingested into the body. } \\
\text { Therefore, some data will need more } \\
\text { protection than others. For example, a sensor } \\
\text { tracking pallets, being shipped overseas is } \\
\text { unlikely to transmit such sensitive personal } \\
\text { data by comparison with a wearable fitness } \\
\text { devices which, for instance, might be } \\
\text { transmitting medical information. }\end{array}$ & $\begin{array}{l}\text { Addressing the challenges linked to the growing } \\
\text { ethical issues on Big Data Analytics, a major } \\
\text { problem in Industry 4.0, Paul Bernal (2016; cited } \\
\text { by Chen et al., 2018) examined internet } \\
\text { surveillance from human rights perspectives, } \\
\text { using the framework of European Conventions of } \\
\text { Human Rights (ECHR). The paper re-evaluated } \\
\text { commercial and governmental data gathering and } \\
\text { surveillance and how they are treated as separate } \\
\text { and different, rather than intrinsically and } \\
\text { inextricably linked. Although the study raised the } \\
\text { bar for justification and need for a new balance to } \\
\text { be found, in political debate, in law, and in } \\
\text { business decision-making, it did not proffer any } \\
\text { practical solution to the problems identified. Also } \\
\text { in a bid to offer practical solution to the daunting } \\
\text { challenges of ethical issues associated with big } \\
\text { data and other emerging technologies, Kenciak } \\
\text { (2017; cited by Rehman et al., 2019) investigated } \\
\text { the legal and institutional aspect of cybersecurity } \\
\text { and cyberspace protection under the EU legal } \\
\text { framework. }\end{array}$ \\
\hline
\end{tabular}

Table 4: Thematic landscape in terms of broad themes and sub -theme (article streams)

\begin{tabular}{|c|c|c|}
\hline $\begin{array}{l}\text { BDSCA(them number):broad theme } \\
\text { reflecting the main focus }\end{array}$ & $\begin{array}{l}\text { Article stream (number): showing the } \\
\text { conceptual underpinning of the sub- } \\
\text { theme focus }\end{array}$ & $\begin{array}{l}\text { Conceptual standpoints of selective articles (full } \\
\text { list of the authors) }\end{array}$ \\
\hline $\begin{array}{l}\text { Privacy (1): In many cases, the consumer is } \\
\text { unaware that the companies that have } \\
\text { supplied specific items are carrying out data } \\
\text { processing. }\end{array}$ & $\begin{array}{l}\text { Article stream (14): the focus is to explore } \\
\text { the need for firms to ensure that consent is } \\
\text { obtained from individuals in relation to data } \\
\text { collection. The data that is being transmitted } \\
\text { could give sensitive details about its owner's } \\
\text { health or religion. For example, if Halal or } \\
\text { diabetic food is ordered, a typical instance of } \\
\text { a fridge connected to internet divulging this } \\
\text { privacy. }\end{array}$ & $\begin{array}{l}\text { Baijian et al (2018; cited by Baig et al., 2017) } \\
\text { provide a thorough survey of IoT security and } \\
\text { privacy challenges from the perspectives of } \\
\text { technologies and architecture used. Their work } \\
\text { focused on IoT intrinsic vulnerability and their } \\
\text { implications for the fundamental information } \\
\text { security challenges in confidentiality, integrity, } \\
\text { and availability. } \\
\text { Similarly, Luccipicini (2016; cited by Buenrostro } \\
\text { et al., 2018) focused on the social and ethical } \\
\text { aspects of drone use and identified key areas of } \\
\text { concerns connected with commercial drone use. } \\
\text { The findings specifically contributes to the } \\
\text { technology studies and media ethics research by } \\
\text { providing insights into the state of public } \\
\text { knowledge concerning commercial drones from } \\
\text { ethical, privacy and legal perspectives. }\end{array}$ \\
\hline
\end{tabular}




\section{Results}

This research conceptualised, developed and validated the dimensions of Big Data Analytics and Supply Chain applications, as well as Ethical, Security and Privacy considerations based on 120 articles filtered from 48 mainstream academic journals as listed in table 3 . The study embraced a systematic approach to establish rigor throughout the review: this was based on a similar approach used by Vaithianathan (2010; cited by Wamba, 2016) in e-commerce research and Benedettini and Neely (2012; cited by Phase and Mhetre, 2018) in service systems research. The study adopted a protocol that described the criteria, scope, and methodology at each step.

Additionally, the thematic landscape was designed around the conceptual standpoints along three top categories including Big Data Analytics, Applications, and Ethics and Privacy. The thematic landscape was further expanded into broad level themes and sub-themes as shown in Tables 4 and 5. As such, a total number of 7 broad themes and 14 sub-themes were identified. The tables were designed to provide a clear understanding of the specific conceptual underpinnings as contained in the thematic landscape. 
Table 5. Detailed timeline of BDSCA

\begin{tabular}{|c|c|c|c|c|c|c|c|c|c|c|c|c|c|c|c|c|c|}
\hline $\begin{array}{l}\text { Article } \\
\text { Stream } \\
(\mathbf{A S})\end{array}$ & 2005 & 2006 & 2007 & 2008 & 2009 & 2010 & 2011 & 2012 & 2013 & 2014 & 2015 & 2016 & 2017 & 2018 & 2019 & 2020 & Total \\
\hline \multicolumn{18}{|c|}{ Big Data Analytics } \\
\hline AS 1 & & & & & & & & 1 & 1 & & 1 & & & 2 & 1 & 1 & 7 \\
\hline AS 2 & & & & & & & & & & 1 & & 2 & & 1 & & & 4 \\
\hline AS 3 & & & & & & & & & 1 & & 2 & & 3 & & & & 6 \\
\hline $\mathrm{AS} 4$ & & & & & & & & & 1 & & 2 & & & 2 & 3 & & 8 \\
\hline AS 5 & & & & & & & & & 2 & & & 1 & & & 3 & & 6 \\
\hline AS 6 & & & & & & & & & & & 2 & & & & 1 & & 3 \\
\hline \multicolumn{18}{|c|}{ Applications } \\
\hline A S 7 & & & & & & & & & 1 & & 2 & & 6 & & 3 & 1 & 13 \\
\hline AS 8 & & & & & & & & & & & 1 & 5 & 4 & & & & 10 \\
\hline AS 9 & & & & & & & & & 2 & 2 & 1 & & 5 & 1 & 4 & & 17 \\
\hline AS 10 & & & & & & & & & & & 1 & 3 & & & 2 & & 6 \\
\hline AS 11 & & & & & & & & & & 3 & 2 & & 1 & 1 & & & 7 \\
\hline AS 12 & & & & & & & & & 5 & 1 & 1 & & 2 & & 1 & & 10 \\
\hline \multicolumn{18}{|l|}{ Ethics } \\
\hline AS 13 & & & & & & & & & 2 & 1 & 5 & 1 & 3 & & 2 & & 14 \\
\hline \multicolumn{18}{|l|}{ Privacy } \\
\hline AS 14 & & & & & & & & & 1 & 4 & 1 & 3 & & 1 & 1 & & 11 \\
\hline Total & & & & & & & & & & & & & & & & & 120 \\
\hline
\end{tabular}

\section{Discussion and contributions}

This study presents a systematic and comprehensive review of current and past studies of topical issues in Big Data Supply Chain Analytics and the challenging issues of ethics, privacy and security considerations, as well as the implications to society, businesses and industry. The research is very novel as other review work hardly address the operational challenges in supply chain including security, ethical and privacy issues relating to the expansion and evolution of Big Data analytics.

Furthermore, the existing research on Big Data Analytics and SCM is focused on traditional supply chain information, and paid little attention to the significant data-driven prospects associated with big data analytics. Most reviewed research work often justifies this approach 
in the sense that most of the big data techniques is not useful to supply chain operations because of its raw state of data, and the fact that most of the supply chain data and information are often held captive inside organisational silos.

The systematic rigor adopted in this study is more evident, particularly in clear recognition of intrusive and invasive nature of big data and its impacts on individuals' freedom and ramifications to the entire society. More so, the comprehensive review demonstrates clarity, and brought to bear what the issues are. There are also limited empirical studies that investigate the integration of industry 4.0 with current management approach to deliver high level performance. This is an area of opportunity for further research.

Despite the prospects of the application of big data techniques, particularly, from the perspectives of $3 \mathrm{Vs}$ (volume, velocity, and Variety), issues of security and privacy, ramifications for business, society and industry is still an unexplored territory. This paper offers insights and outlined recommendations in terms of the role of the government, society and individual, as well as the responsibility of business owners in upholding the perceived duty of care to their customers in an interconnected cyber-physical global economy with a pervasive and entrenched culture of data generation, collection and synthesis. The emergence and eventual adoption of $5 \mathrm{G}$ technology on a global scale will place Big Data and Business Analytics or the principles underpinning BDBA at centre stage of debates around the balance between privacy, security, and social order and business benefits. There is therefore the need for research into the opportunity costs of BDBA tools in a $5 \mathrm{G}$ technology era. It is our contention that such research will build on the work reported in the literature on BDBA we have explored, reviewed and classified in this study.

\section{References:}

Accenture 2014. Big Data Analytics in Supply Chain: Hype or Here to Stay? Accenture Global Operations Megatrends Study, pp. 1-20

https://www.accenture.com/t20160106T194441_w_/fien/_acnmedia/Accenture/Conversion -Assets/DotCom/Documents/Global/PDF/Digital_1/Accenture-Global-OperationsMegatrends-Study-Big-Data-Analytics-v2.pdf

Akter, S. and Wamba, S.F., 2016. "Big data analytics in E-commerce: a systematic review and agenda for future research", Electronic Markets, 26(2), pp.173-194. https://link.springer.com/content/pdf/10.1007/s12525-016-0219-0.pdf 
AlDairi, A. and Tawalbeh, L. 2017. "Cyber security attacks on smart cities and associated mobile technologies", Procedia Computer Science, 109(2017), pp.1086-1091. https://doi.org/10.1016/j.procs.2017.05.391

Ambore, S., Richardson, C., Dogan, H., Apeh, E. and Osselton, D., 2017. "A resilient cybersecurity framework for Mobile Financial Services (MFS)", Journal of Cyber Security Technology, 1(3-4), pp.202-224. https://doi.org/10.1080/23742917.2017.1386483

Ani, U.P.D., He, H. and Tiwari, A., 2017. "Review of cybersecurity issues in industrial critical infrastructure: manufacturing in perspective", Journal of Cyber Security Technology, 1(1), pp.32-74. https://doi.org/10.1080/23742917.2016.1252211

Awwad, M., Kulkarni, P., Bapna, R. and Marathe, A. 2018. "September. Big Data Analytics in Supply Chain: A Literature Review", In Proceedings of the International Conference on Industrial Engineering and Operations Management, Washington DC, USA, September 2729, (2018), pp. 418-425.

Baig, Z.A., Szewczyk, P., Valli, C., Rabadia, P., Hannay, P., Chernyshev, M., Johnstone, M., Kerai, P., Ibrahim, A., Sansurooah, K. and Syed, N., 2017. "Future challenges for smart cities: Cyber-security and digital forensics", Digital Investigation, 22, pp.3-13. https://doi.org/10.1016/j.diin.2017.06.015

Barbosa, M.W., Vicente, A.D.L.C., Ladeira, M.B. and Oliveira, M.P.V.D., 2018. "Managing supply chain resources with Big Data Analytics: a systematic review", International Journal of Logistics Research and Applications, 21(3), pp.177-200. https://doi.org/10.1080/13675567.2017.1369501

Barbosa, M.W., Vicente, A.D.L.C., Ladeira, M.B. and Oliveira, M.P.V.D., 2018. "Managing supply chain resources with Big Data Analytics: a systematic review", International Journal of Logistics Research and Applications, 21(3), pp.177-200. https://doi.org/10.1080/13675567.2017.1369501

Ben-Daya, M., Hassini, E. and Bahroun, Z., 2019. "Internet of things and supply chain management: a literature review", International Journal of Production Research, 57(15-16), pp.4719-4742. https://doi.org/10.1080/00207543.2017.1402140

Bernal, P., 2016. "Data gathering, surveillance and human rights: recasting the debate", Journal of Cyber Policy, 1(2), pp.243-264.

Boyd, D. and Crawford, K., 2012. "Critical questions for big data: Provocations for a cultural, technological, and scholarly phenomenon", Information, communication \& society, 15(5), pp.662-679.

Buenrostro, E., Cyrus, D., Le, T. and Emamian, V., 2018. "Security of IoT Devices", Journal of Cyber Security Technology, 2(1), pp.1-13. https://doi.org/10.1080/23742917.2018.1474592 
Bumblauskas, D., Nold, H., Bumblauskas, P. and Igou, A. (2017). "Big data analytics: transforming data to action” Business Process Management Journal, 23(3), pp. 703-720. https://doi.org/10.1108/BPMJ-03-2016-0056

Chae, B.K., 2015. "Insights from hashtag\# supply chain and Twitter Analytics: Considering Twitter and Twitter data for supply chain practice and research", International Journal of Production Economics, 165(2015), pp.247-259.

Chavez, R., Yu, W., Jacobs, M.A. and Feng, M., 2017. "Data-driven supply chains, manufacturing capability and customer satisfaction", Production Planning and Control, 28(1112), pp.906-918.

Chehbi-Gamoura, S., Derrouiche, R., Damand, D. and Barth, M., 2020. "Insights from big Data Analytics in supply chain management: an all-inclusive literature review using the SCOR model”, Production Planning \& Control, 31(5), pp.355-382.

Chehbi-Gamoura, S., Derrouiche, R., Damand, D. and Barth, M., 2020. "Insights from big Data Analytics in supply chain management: an all-inclusive literature review using the SCOR model”, Production Planning and Control, 31(5), pp.355-382.

Chen, C.P. and Zhang, C.Y., 2014. "Data-intensive applications, challenges, techniques and technologies: A survey on Big Data", Information sciences, 275(2014), pp.314-347. https://doi.org/10.1016/j.ins.2014.01.015

Chen, G., Sabato, Z. and Kong, Z., 2018. "Formal interpretation of cyber-physical system performance with temporal logic", Cyber-Physical Systems, 4(3), pp.175-203. https://doi.org/10.1080/23335777.2018.1510857

Chen, S., Xu, H., Liu, D., Hu, B. and Wang, H., 2014. "A vision of IoT: Applications, challenges, and opportunities with china perspective", IEEE Internet of Things journal, 1(4), pp.349-359. DOI: $\underline{\text { 10.1109/JIOT.2014.2337336 }}$

de Sousa Jabbour, A.B.L., Jabbour, C.J.C., Godinho Filho, M. and Roubaud, D., 2018. "Industry 4.0 and the circular economy: a proposed research agenda and original roadmap for sustainable operations", Annals of Operations Research, 270(1-2), pp.273-286.

Din, I.U., Guizani, M., Rodrigues, J.J., Hassan, S. and Korotaev, V.V., 2019. "Machine learning in the Internet of Things: Designed techniques for smart cities", Future Generation Computer Systems, 100 (2019), pp.826-843.

Dubey, R., Altay, N., Gunasekaran, A., Blome, C., Papadopoulos, T. and Childe, S.J., 2018. "Supply chain agility, adaptability and alignment", International Journal of Operations and Production Management, 38(1), pp. 129-148. https://doi.org/10.1108/IJOPM-04-2016-0173 
Elmaghraby, A.S. and Losavio, M.M., 2014. "Cyber security challenges in Smart Cities: Safety, security and privacy", Journal of advanced research, 5(4), pp.491-497.

Fatorachian, H. and Kazemi, H., 2018. "A critical investigation of Industry 4.0 in manufacturing: theoretical operationalisation framework", Production Planning \& Control, 29(8), pp.633-644. https://doi.org/10.1080/09537287.2018.1424960

Einav, L., and Levin, J. 2014. 'Economics in the age of big data.' Journal of Economics, 346(2014), pp. 0036-80705.

Fernando, Y., Chidambaram, R.R. and Wahyuni-TD, I.S., 2018. "The impact of Big Data analytics and data security practices on service supply chain performance", Benchmarking: An International Journal, 25(9), pp. 4009-4034. https://doi.org/10.1108/BIJ-07-2017-0194

Festa, G., Safraou, I., Cuomo, M.T. and Solima, L. (2018). "Big data for big pharma: Harmonizing business process management to enhance ambidexterity", Business Process Management Journal, 24(5), pp. 1110-1123. https://doi.org/10.1108/BPMJ-10-2017-0272

Financial Times Archive (2015).

Gartner, M., and Brocca. R. 2015. 'Deconstructing supply chain analytics." Journal of Supply Chain Management, 25(2015): 200-326.

Gunasekaran, A., Papadopoulos, T., and Dubey, R., and Childe, S.J.Stephen J. 2016. ' 'Big data and predictive analytics for supply chain and organizational performance.' Journal of Business Research, 70(2016): pp.308-31. https://doi.org/10.1016/j.jbusres.2016.08.004

Gruda, D. and Hasan, S., 2019. "Feeling anxious? Perceiving anxiety in tweets using machine learning", Computers in Human Behaviour, 98(2019), pp.245-255. https://doi.org/10.1016/j.chb.2019.04.020

Guo, Z., Ngai, E., Yang, C. and Liang, X., 2015. “An RFID-based intelligent decision support system architecture for production monitoring and scheduling in a distributed manufacturing environment", International journal of production economics, 159, pp.16-28.

Harris, I., Wang, Y. and Wang, H., 2015. "ICT in multimodal transport and technological trends: Unleashing potential for the future", International Journal of Production Economics, 159(2015), pp.88-103. https://doi.org/10.1016/j.ijpe.2014.09.005

Hashem, I.A.T., Yaqoob, I., Anuar, N.B., Mokhtar, S., Gani, A. and Khan, S.U., 2015. "The rise of "big data" on cloud computing: Review and open research issues", Information systems, 47(2015), pp.98-115. https://doi.org/10.1016/j.is.2014.07.006 
Hofmann, E., 2017. "Big data and supply chain decisions: the impact of volume, variety and velocity properties on the bullwhip effect", International Journal of Production Research, 55(17), pp.5108-5126. https://doi.org/10.1080/00207543.2015.1061222

Ivanov, D. and Dolgui, A., 2020. "A digital supply chain twin for managing the disruption risks and resilience in the era of Industry 4.0", Production Planning \& Control, pp.1-14. https://doi.org/10.1080/09537287.2020.1768450

Kenda, K. and Mladenić, D., 2018. "Autonomous sensor data cleaning in stream mining setting", Business Systems Research Journal, 9(2), pp.69-79. DOI: https://doi.org/10.2478/bsrj-2018-0020

Kshetri, N., 2014. "Big data' s impact on privacy, security and consumer welfare", Telecommunications Policy, 38(11), pp.1134-1145. https://doi.org/10.1016/j.telpol.2014.10.002

Kusiak, A., 2018. "Smart manufacturing”, International Journal of Production Research, 56(12), pp.508-517. https://doi.org/10.1080/00207543.2017.1351644

Lamba, K. and Singh, S.P., 2017. "Big data in operations and supply chain management: current trends and future perspectives", Production Planning \& Control, 28(11-12), pp.877890. https://doi.org/10.1080/09537287.2017.1336787

Li, J., Tao, F., Cheng, Y. and Zhao, L., 2015. "Big data in product lifecycle management", The International Journal of Advanced Manufacturing Technology, 81(1-4), pp.667-684.

Luppicini, R. and So, A., 2016. "A technoethical review of commercial drone use in the context of governance, ethics, and privacy”, Technology in Society, 46, pp.109-119. https://doi.org/10.1016/j.techsoc.2016.03.003

Mahrt, M. and Scharkow, M., 2013. "The value of big data in digital media research", Journal of Broadcasting and Electronic Media, 57(1), pp.20-33. https://doi.org/10.1080/08838151.2012.761700

Makris, D., Hansen, Z.N.L. and Khan, O., 2019. “Adapting to supply chain 4.0: an explorative study of multinational companies", In Supply Chain Forum: An International Journal, 20(2), pp. 116-131.

Maple, C., 2017. "Security and privacy in the internet of things", Journal of Cyber Policy, 2(2), pp.155-184. https://doi.org/10.1080/23738871.2017.1366536

Mendez Mena, D., Papapanagiotou, I. and Yang, B., 2018. "Internet of things: Survey on security”, Information Security Journal: A Global Perspective, 27(3), pp.162-182. 
Mikalef, P., Boura, M., Lekakos, G. and Krogstie, J., 2019. "Big data analytics and firm performance: Findings from a mixed-method approach", Journal of Business Research, 98(2019), pp.261-276. https://doi.org/10.1016/j.jbusres.2019.01.044

Moeuf, A., Pellerin, R., Lamouri, S., Tamayo-Giraldo, S. and Barbaray, R., 2018. "The industrial management of SMEs in the era of Industry 4.0", International Journal of Production Research, 56(3), pp.1118-1136. https://doi.org/10.1080/00207543.2017.1372647

Mueller, S.D. and Jensen, P., 2017. "Big data in the Danish industry: application and value creation", Business Process Management Journal. 23(3), pp. 645-670. https://doi.org/10.1108/BPMJ-01-2016-0017

Musa, A. and Dabo, A.A.A., 2016. "A review of RFID in supply chain management: 20002015”, Global Journal of Flexible Systems Management, 17(2), pp.189-228. https://doi.org/10.1007/s40171-016-0136-2

Niebel, T., Rasel, F. and Viete, S., 2019. "BIG data-BIG gains? Understanding the link between big data analytics and innovation", Economics of Innovation and New Technology, 28(3), pp.296-316. https://doi.org/10.1080/10438599.2018.1493075

Oberländer, A.M., Röglinger, M., Rosemann, M. and Kees, A., 2018. "Conceptualizing business-to-thing interactions-A sociomaterial perspective on the Internet of Things", European Journal of Information Systems, 27(4), pp.486-502. https://doi.org/10.1080/0960085X.2017.1387714

Opresnik, D. and Taisch, M., 2015. "The value of big data in servitization", International journal of production economics, 165, pp.174-184. https://doi.org/10.1016/j.ijpe.2014.12.036

Phase, A. and Mhetre, N., 2018. "Using IoT in Supply Chain Management" International Journal of Engineering and Techniques, 4 (2), pp. 973-979.

Psannis, K.E., Xinogalos, S. and Sifaleras, A., 2014. "Convergence of Internet of things and mobile cloud computing”, Systems Science \& Control Engineering: An Open Access Journal, 2(1), pp.476-483. https://doi.org/10.1080/21642583.2014.913213

Queiroz, M.M. and Telles, R., 2018. "Big data analytics in supply chain and logistics: An empirical approach", The International Journal of Logistics Management, 29(2), pp. 767-783. https://doi.org/10.1108/IJLM-05-2017-0116

Raman, S., Patwa, N., Niranjan, I., Ranjan, U., Moorthy, K. and Mehta, A., 2018. "Impact of big data on supply chain management", International Journal of Logistics Research and Applications, 21(6), pp.579-596. https://doi.org/10.1080/13675567.2018.1459523

Rodríguez-Mazahua, L., Rodríguez-Enríquez, C.A., Sánchez-Cervantes, J.L., Cervantes, J., García-Alcaraz, J.L. and Alor-Hernández, G., 2016. "A general perspective of Big Data: 
applications, tools, challenges and trends", The Journal of Supercomputing, 72(8), pp.30733113.

Salleh, K.A. and Janczewski, L., 2016. "Technological, organizational and environmental security and privacy issues of big data: A literature review", Procedia Comput. Sci, 100, pp.1928.

Subashini, S. and Kavitha, V., 2011. "A survey on security issues in service delivery models of cloud computing", Journal of network and computer applications, 34(1), pp.1-11. https://doi.org/10.1016/j.jnca.2010.07.006

Tan, K.H., Zhan, Y., Ji, G., Ye, F. and Chang, C., 2015. "Harvesting big data to enhance supply chain innovation capabilities: An analytic infrastructure based on deduction graph", International Journal of Production Economics, 165(2015), pp.223-233. https://doi.org/10.1016/j.ijpe.2014.12.034

Tortorella, G., Miorando, R. and Mac Cawley, A.F., 2019. "The moderating effect of Industry 4.0 on the relationship between lean supply chain management and performance improvement", Supply Chain Management-An International Journal, 24(2), pp.301-314.

ur Rehman, M.H., Yaqoob, I., Salah, K., Imran, M., Jayaraman, P.P. and Perera, C., 2019. “The role of big data analytics in industrial Internet of Things", Future Generation Computer Systems, 99, pp.247-259.

Wamba, S.F., Akter, S., Edwards, A., Chopin, G. and Gnanzou, D., 2015. "How 'big data'can make big impact: Findings from a systematic review and a longitudinal case study", International Journal of Production Economics, 165(2015), pp.234-246.

Wallet, A., Stanley, E., and Fawcett, M. 2013. ''Data science, predictive analytics, and Big Data: A revolution that will transform supply chain design and management.' Journal of Business Logistics, 34(2), pp. 77-80.

Yang, C., Huang, Q., Li, Z., Liu, K. and Hu, F., 2017. "Big Data and cloud computing: innovation opportunities and challenges", International Journal of Digital Earth, 10(1), pp.1353. https://doi.org/10.1080/17538947.2016.1239771

Yucelen, T., Haddad, W.M. and Feron, E.M., 2016. "Adaptive control architectures for mitigating sensor attacks in cyber-physical systems", Cyber-Physical Systems, 2(1-4), pp.2452. https://doi.org/10.1080/23335777.2016.1244562

Zhang, H. and Xiao, Y., 2020. "Customer involvement in big data analytics and its impact on B2B innovation”, Industrial Marketing Management, 86, pp.99-108. https://doi.org/10.1016/j.indmarman.2019.02.020 
Zhong, R.Y., Huang, G.Q., Lan, S., Dai, Q.Y., Chen, X. and Zhang, T., 2015. "A big data approach for logistics trajectory discovery from RFID-enabled production data", International Journal of Production Economics, 165, pp.260-272. https://doi.org/10.1016/j.ijpe.2015.02.014 